\section{Using Sparkleberry as a Genetic Source for Machine Harvest Traits for Southern Highbush Blueberry}

\author{
James W. Olmstead ${ }^{1}$, Hilda Patricia Rodríguez Armenta, \\ and Paul M. Lyrene
}

ADDITIONAL INDEX WORDS. Vaccinium arboreum, Vaccinium corymbosum, southern highbush blueberry, blueberry breeding, polyploidy, wide hybridization, interspecific hybridization

SUMMARY. Because of financial and labor concerns, growers are interested in using machine harvesting for fruit destined to be fresh marketed. Machine harvest of highbush blueberry (Vaccinium corymbosum) has typically been used to obtain large volumes of fruit destined for processing. Bush architecture, easy detachment of mature berries compared with immature berries, loose fruit clusters, small stem scar, firm fruit, and a concentrated ripening period are breeding goals to develop cultivars amenable to machine harvest. In the University of Florida (UF) southern highbush blueberry [SHB (Vaccinium corymbosum hybrids)] breeding program, sparkleberry (Vaccinium arboreum) has been used in wide crosses in an attempt to introgress traits that may be valuable for machine harvesting, namely upright growth habit with a narrow crown and long flower and fruit pedicels creating loose fruit clusters. Two eras of sparkleberry hybridization experiments have occurred since the early 1980s. The first era used darrow's evergreen blueberry (Vaccinium darrowii) as a bridge between sparkleberry and tetraploid SHB, with the recently released cultivar FL 01-173 (sold under the trademarked name Meadowlark) as an example of the end product. The second era has used chromosome doubling to develop polyploid sparkleberry selections that were directly crossed with tetraploid $S H B$. After 1 year of evaluation, a $\mathrm{SHB} \times(\mathrm{SHB} \times$ sparkleberry $)$ population developed for linkage and quantitative trait locus mapping showed abundant variation for length:width ratio of the plant, but similarity to the highbush phenotype for peduncle and pedicel length of the fruit. These first evaluations indicate evidence of introgression and provide an initial step toward improved cultivars for mechanical harvesting.

$\mathrm{M}$ achine or mechanically aided harvest has been used since the mid-twentieth century for lowbush blueberry (Vaccinium angustifolium), highbush blueberry, and rabbiteye blueberry (Vaccinium virgatum). The harvest equipment has evolved over the years, but the utilization of the harvested product has remained constant: machine-harvested fruit are predominantly destined for processed blueberry (Vaccinium species and hybrids) products because

Horticultural Sciences Department, University of Florida, 2211 Fifield Hall, Gainesville, FL 32611

This paper was part of the workshop " Mechanized Harvest of Blueberries for the Fresh Market" held 2 Aug. 2012 at the ASHS Conference, Miami, FL, and sponsored by the Viticulture and Small Fruits (VSF) Working Group.

This study was funded by the USDA-NIFA Specialty Crop Research Initiative (A multi-disciplinary approach to sustainability and profitability of U.S blueberry production using the tree-like species $\mathrm{Vac}$ cinium arboreum, Award No. 2009-51181-06021).

We gratefully acknowledge the support and assistance of David Norden and Werner Collante.

${ }^{1}$ Corresponding author. E-mail: jwolmstead@ufl.edu. of the potential for fruit damage leading to reduced marketability and postharvest life. In the most recent comprehensive survey of production practices, Strik and Yarborough (2005) reported that the percentage of machine-harvested highbush, rabbiteye, and SHB acreage used for processing ranged from $50 \%$ in Washington State to $100 \%$ in Georgia and Michigan. The authors found that a substantially lower percentage of fruit destined for fresh utilization was machine harvested, and the highest percentages were often in areas producing rabbiteye blueberries. However, the percentages of acreage harvested by machine for both processed and fresh utilization had increased from the survey by Moore (1994). The authors of both reports indicated that the trend for machine harvest would continue increasing, a trend that has been consistent for at least the past two decades. Our objectives were to identify the traits necessary for machine harvest for fresh fruit (MFF) in SHB, and to summarize the history and current progress of using sparkleberry as a genetic source for MFF traits.

\section{Machine harvest for fresh fruit marketing}

To facilitate MFF, both engineering and biological solutions are needed. At least one attempt has been made to design a machine harvester suitable for MFF (Peterson et al., 1997; Takeda et al., 2008). On the biological side, the basic ideotype of a highbush blueberry plant for machine harvest was described by Galletta (1975) and summarized in Dale et al. (1994). An ideal highbush blueberry for machine harvest would have: upright bush architecture, few low-growing canes, a narrow crown, easy detachment of mature berries compared with immature berries, loose fruit clusters, a small stem scar, firm fruit, and a concentrated ripening period. These attributes are central breeding goals in development of cultivars amenable to machine harvesting.

The focus on upright bush architecture and narrow crowns is largely due to the predominant over-the-row machine harvester designs. Upright bushes with stocky canes performed well in early evaluations of machine harvest potential using handheld vibrators (Galletta and Mainland, 1971). The shape fits the tunnel design commonly employed in harvesters. In overthe-row harvesters, fruit falls to a series of spring-loaded plates often termed "fish scales" that move in and out at the base of the machine to conform to the plant crown. A wide crown results in more fruit being dropped to the ground during the harvest process. During machine harvesting of highbush blueberries, ground losses in the $10 \%$ to $25 \%$ range have been reported (Mainland, et al., 1975; van Dalfsen and Gaye, 1999), although this figure has approached $50 \%$ in at least one

\begin{tabular}{llll}
\hline $\begin{array}{l}\text { Units } \\
\begin{array}{l}\text { To convert U.S. to SI, } \\
\text { multiply by }\end{array}\end{array}$ & U.S. unit & SI unit & $\begin{array}{l}\text { To convert SI to U.S., } \\
\text { multiply by }\end{array}$ \\
\hline 25.4 & inch(es) & $\mathrm{mm}$ & 0.0394
\end{tabular}


study (Mainland et al., 1975). Restricting crown width by physically tying a piece of tubing around the crown reduced ground losses by $40 \%$ (Rohrbach and Mainland, 1989), while pruning strategies to limit ground loss may also be an option (Takeda et al., 2008).

Fruit detachment and cluster architecture are also key components of machine harvest efficiency. The ideal cultivar would have fruit that require low detachment force at the mature blue stage compared with green fruit. Natural variation in fruit detachment force among SHB selections has been documented (Sargent et al., 2010), and abscission agents such as ethephon and methyl jasmonate have been tested with varying results to reduce fruit detachment force as an aid for mechanical harvest (Malladi et al., 2012). An abscission zone between the fruit and pedicel resulting in a small, dry stem scar is desirable for MFF. Variation for these traits is still high among highbush blueberry, rabbiteye blueberry, and SHB germplasm as stem scar was recently ranked among breeders as one of the top five priorities for selection (Finn et al., 2013). Commercially available destemming equipment is available and often employed in process highbush and rabbiteye blueberry packing lines; fewer packing lines dedicated to fresh packing use destemmers because of the potential for fruit damage. Tight clusters resulting from short pedicel lengths tend to have reduced efficiency during machine harvest. A common strategy employed by those using MFF is to use handharvesting for at least the first picking, thereby removing some fruit from many clusters before the first machine harvest (W.O. Cline, personal communication). In most production regions, the first harvest is the highest-valued fruit, making this strategy economically attractive.

Fruit firmness is often thought to play a critical role in suitability for machine harvest. Evaluations comparing hand and machine-harvested highbush blueberry fruit have consistently shown a significant decrease in firmness of machine-harvested fruit, which was directly correlated to an increase in unmarketable fruit and decay in postharvest storage (Ballinger et al., 1973; Brown et al., 1996; Mainland et al., 1975). Among a large group of highbush and hybrid blueberry cultivars, an approximate 2.4-fold difference in fruit firmness was measured (Ehlenfeldt, 2005; Ehlenfeldt and Martin, 2002). Many of the firmer selections were recent breeding releases, indicating that progress in developing firmer highbush blueberry cultivars has been made (Ehlenfeldt, 2005).

A concentrated ripening period may ultimately prove to be the most important economic factor in determining feasibility of MFF. In high-value production areas and times, handharvest intervals may be as short as $3 \mathrm{~d}$ as growers often seek to maximize the volume of fruit harvested in the highvalue window. However, because of the inherent losses (ground drops, green fruit picked, bruising leading to soft fruit) during the mechanical harvest process, a much larger volume of fruit must be ripe at the same time to realize maximum efficiency. Galletta (1975) discussed disadvantages that might result from selection for concentrated ripening period. He suggested a reduction in total yield would be likely when all flower buds matured simultaneously, and concentrated maturity increases the potential for crop loss because of environmental risks. Several cultivars (Croatan, Collins, Morrow, Earliblue, and Tifblue) were described that matured over $80 \%$ of their crop in a 7-d period and the fruit held on the plant could retain good fruit quality. Ehlenfeldt (2005) described fruit holding ability-the ability to maintain high levels of fruit firmness after initial ripening has occurred-as it relates to mechanical harvest. He concluded that a concentrated ripening period was more desirable for mechanical harvest than extended holding ability as an extended holding ability led to yield reductions. It was emphasized that breeders should strive to develop cultivars incorporating both concentrated ripening periods and excellent holding ability.

\section{History of breeding with sparkleberry}

The major cultivated blueberries in North America (highbush, lowbush, rabbiteye, and $\mathrm{SHB}$ ) belong to the section Cyanococcus of the Vaccinium genus. In addition to the cultivated examples, several wild species in the section Cyanococcus have made a significant contribution to the $\mathrm{SHB}$ gene pool, most notably darrow's evergreen blueberry (Brevis et al., 2008; Lyrene, 2008). Lyrene et al. (2003) extensively reviewed the use of hybridization between members of the Cyanococcus section as a tool in blueberry breeding. The combination of a high level of similarity in chromosome morphology and frequent production of unreduced gametes has often been used to bridge ploidy barriers and introgress desirable traits from different species. However, successful hybridization between species outside of the section Cyanococcus with either cultivated or uncultivated members of the Cyanococcus section has been less frequent. Thus, it is intersectional crosses and not interspecific crosses that present the greatest challenges to breeders.

The intersectional cross between sparkleberry and SHB has been a long-term goal in the UF SHB breeding program. Sparkleberry, a diploid member of the section Batodendron, is native to the southeastern United States and is often found as a small tree (Camp, 1945; Vander Kloet, 1988). Sparkleberry plants often grow on soils that are drier, have lower organic matter, and higher soil $\mathrm{pH}$ than highbush blueberry can survive on (Lyrene, 1991, 1997). Sparkleberry fruit tend to be borne on longer pedicels, and are small, black, have large seeds and abundant sclereids, resulting in a gritty, unpleasant sensory experience (Lyrene, 1997). However, the potential to introgress adaptive traits not present in cultivated germplasm led to the initiation of a program in 1981 to use sparkleberry in breeding efforts (Lyrene, 1991).

In these first experiments, sparkleberry pollen was used to pollinate darrow's evergreen blueberry selections (Lyrene, 1991). Although individual crosses varied greatly, a significant number of seedlings were recovered, and the most vigorous of these hybrids were transplanted to a field for continued observation (Lyrene, 1991; Lyrene and Brooks, 1995). The fertility level for these plants was extremely low compared with cultivated highbush blueberries, but they were allowed to open-pollinate in the presence of many other blueberry species. Most of the hybrids flowered abundantly, so even with low fruit set and poor seed development there were several years where over 1000 berries per plant were 
harvested. The seedling plants developed from the open pollination of these darrow's evergreen blueberry $\times$ sparkleberry hybrids were termed MIK plants (mother is known) in the UF breeding program (Lyrene and Brooks, 1995). These open-pollinated progeny were tetraploid or near tetraploid and were highly variable, but in general showed morphological variation consistent with introgression of sparkleberry traits, and possessed higher fertility than the original darrow's evergreen blueberry $x$ sparkleberry hybrids (Brooks and Lyrene, 1998a, 1998b). Lyrene and Brooks (1995) suggested that some of the first backcrosses between these MIK parents and SHB cultivars were approaching cultivar quality. Over several years, more than 1000 seedlings were evaluated from the MIK $\times$ $\mathrm{SHB}$ crosses, with the following general characteristics: highly vigorous; small to medium fruit size; highly variable in ripening period; tendency toward evergreen leaves; and mediocre firmness, scar, texture, and flavor
(Lyrene, 1997). The highest quality seedlings from these crosses were backcrossed again to $\mathrm{SHB}$ cultivars for two selection cycles, and these seedlings have essentially been integrated into the UF SHB breeding germplasm. No additional effort has been made to specifically select and track these selections.

Direct crosses between sparkleberry and tetraploid SHB were not successful (Lyrene, 1997), while reciprocal crosses between sparkleberry and diploid highbush blueberry (Vaccinium fuscatum) produced viable seed and offspring (Chavez and Lyrene, 2010), indicating that sparkleberry may not produce unreduced gametes. Thus, the evidence suggested that direct hybridization between sparkleberry and tetraploid SHB may only be possible after chromosome doubling of the sparkleberry genome. In 2004-06, open-pollinated sparkleberry seed were treated with colchicine in an attempt to induce chromosome doubling (Lyrene, 2011; Lyrene and

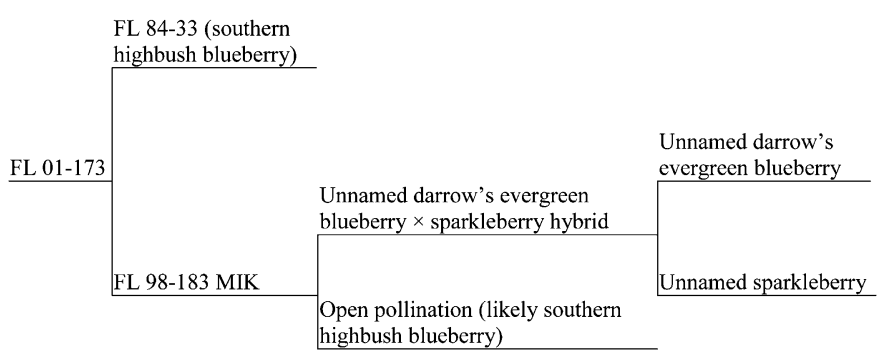

Fig. 1. Pedigree of 'FL 01-173' (Meadowlark ${ }^{\mathrm{TM}}$ ) southern highbush blueberry. MIK is an abbreviation for mother is known, and was used to designate seed lots collected from unnamed hybrid plants with a known field location at the University of Florida Horticulture Unit Farm.

Olmstead, 2012). Morphological indicators were used to select putative polyploid sparkleberry seedlings from the treated seedlings. Large pollen tetrad size was assessed as a final indicator of plants that had been successfully doubled (Lyrene, 2011). These putative polyploid sparkleberry seedlings were then crossed with tetraploid SHB cultivars, and over 1500 hybrids were identified by morphological characteristics in the field. The hybrids were quite variable in vigor and fertility. The most vigorous of these were examined for pollen fertility, and 12 were selected to use in backcrosses to tetraploid SHB cultivars and selections, creating nearly 4000 backcross seedlings (Lyrene, 2011). Characterization has continued to identify additional putative polyploid sparkleberry seedlings after colchicine treatment. More SHB $\times$ sparkleberry hybrids have been generated, along with additional backcross generations.

\section{Progress in introgression of machine harvest traits from sparkleberry}

Although the original rationale for using sparkleberry in SHB breeding was to introgress the traits allowing broader soil adaptation, several traits also have the potential to aid in machine harvesting. The upright, narrow crown, tree-like growth of sparkleberry should effectively reduce ground loss during the machine harvest process similar to earlier experiments with crown restriction (Rohrbach and Mainland, 1989). In addition, longer peduncle and pedicel lengths similar to a sparkleberry

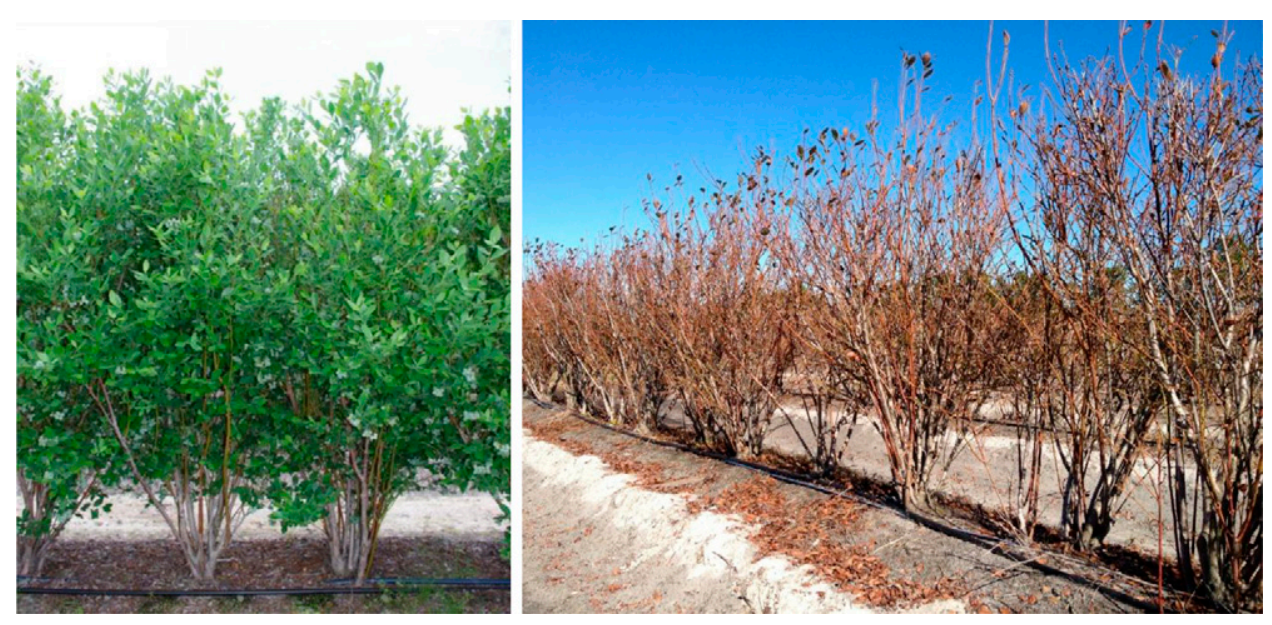

Fig. 2. Example of 6-year-old 'FL 01-173' (Meadowlark ${ }^{\mathrm{TM}}$ ) southern highbush blueberry plants preharvest (left) and during the Florida winter period (right). Note the narrow crown and upright bush architecture. 
fruit cluster should make machine detachment of individual fruit easier. Based on the history of sparkleberry introgression in the UF SHB breeding program, there were two distinct eras of hybridization experiments, each with a different starting germplasm.

DARROW'S EVERGREEN BLUEBERRY AS A BRIDGE BETWEEN TETRAPLOID SHB AND SPARKLEBERRY. The first era used darrow's evergreen blueberry and its propensity for production of unreduced gametes as a bridge to tetraploid chromosome numbers equal to the cultivated SHB. The progress from these experiments was measured in decades, as the first cultivar released with sparkleberry in its pedigree, FL 01-173, took nearly 30 years of development. Interestingly, the example of 'FL 01-173' (Fig. 1) shows that rapid recovery of a commercial-quality phenotype can be made after the initial cross with sparkleberry as the pedigree indicates it is $\approx 1 / 8$ sparkleberry. Much is unknown about the pedigree because of the reliance on open pollination of the darrow's evergreen blueberry $x$ sparkleberry hybrid parents to produce the MIK male parent of 'FL 01-173'. The observation that 'FL 01-173' shows regular male and female fertility and has been used successfully in many subsequent crosses (data not shown) indicates that tetraploid SHB was likely the pollen parent of the MIK used to develop 'FL 01-173'. The upright architecture and long fruit pedicels seem to have been inherited from sparkleberry in 'FL 01-173' (Figs. 2 and 3). When analysis of variance was used to compare pedicel lengths, 'FL 01-173' pedicels averaged $2.3 \mathrm{~mm}$ longer $(P<$ 0.0001 ) than the Florida industry standard cultivar Emerald, which is known for tight clusters and has not performed well for machine harvest.

Genetic markers were used to determine whether sparkleberry genomic regions had been introgressed in 'FL 01-173'. A set of 12 simple sequence repeat markers (CA23F, CA421F, CA855F, CA112F, CA483F, CA794F, NA398, NA961, NA1040, VCC_I2, VCC_J9, and VCC_K4) were used according to Boches et al. (2005) to genotype 24 rabbiteye blueberry and SHB accessions. A similarity matrix was developed from the allele information generated from each locus, and a phenogram was constructed based on an unweighted pair group method with arithmetic mean (UPGMA) analysis
(Fig. 4). The two rabbiteye blueberry cultivars were included as an outgroup. Although the original darrow's evergreen blueberry $\times$ sparkleberry hybrid was not available for comparison, 'FL 01-173' had less similarity to all other SHB cultivars.

DireCT CROSSES BETWEEN TETRAPLOID SHB AND SPARKLEBERRY. In contrast to the first era of sparkleberry crosses, the development pipeline of direct crosses between tetraploid SHB and sparkleberry is less than 10 years old. The key finding that led to this scheme was that although no direct crosses between sparkleberry and tetraploid SHB had ever been successful, crosses between sparkleberry and diploid highbush blueberry were readily made (Chavez and Lyrene, 2010). As an example of the current progress using this breeding methodology,

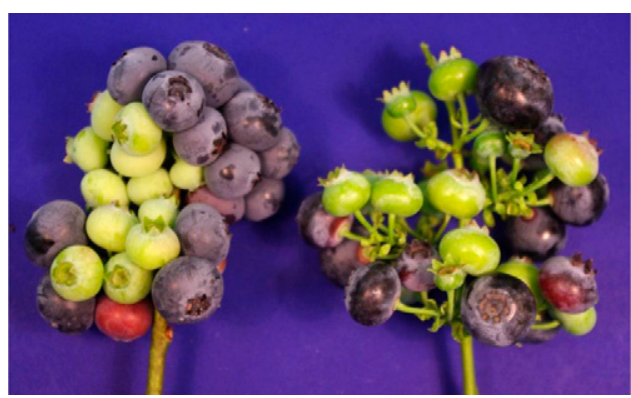

Fig. 3. Comparison of fruit clusters for 'Emerald' (left) and 'FL 01-173' (Meadowlark ${ }^{\mathrm{TM}}$, right) southern highbush blueberry cultivars. Note the long pedicels of 'FL 01-173' creating a loose fruit cluster.

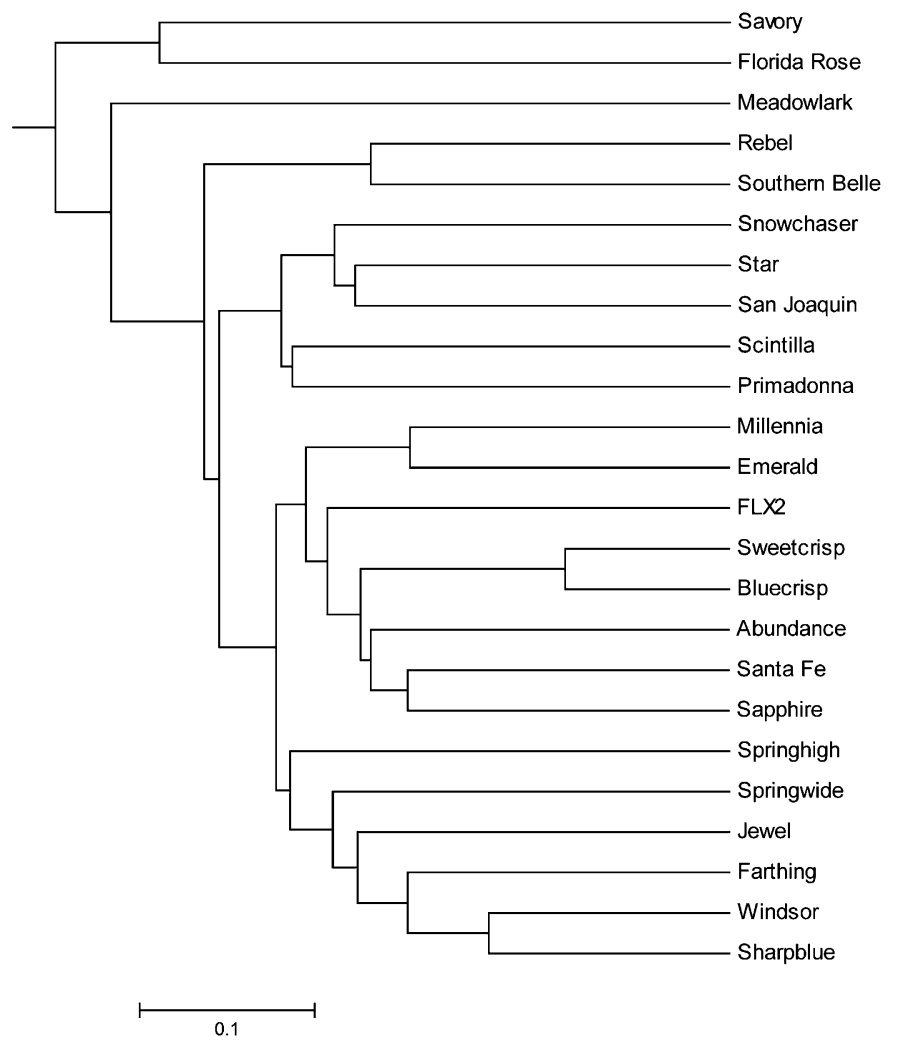

Fig. 4. Unweighted pair group method with arithmetic mean (UPGMA) cluster analysis of 24 southern highbush and rabbiteye blueberry cultivars. The tree was constructed using Dice's coefficient of similarity for alleles of 12 simple sequence repeat markers genotyped for each cultivar. 'Savory' and 'Florida Rose' are both hexaploid rabbiteye blueberry cultivars, while the rest are considered tetraploid southern highbush blueberry cultivars. Note the lack of similarity between Meadowlark ('FL 01-173', with sparkleberry genetic background) compared with the other southern highbush blueberry cultivars. 


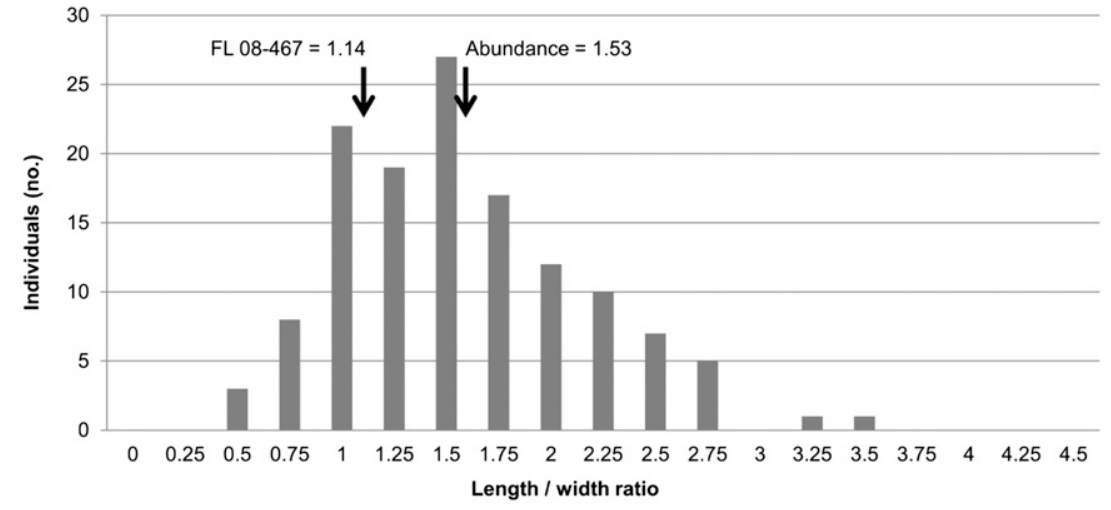

Fig. 5. Histogram of length:width ratio of whole plants for the 'Abundance' southern highbush blueberry $\times$ FL 08-467 population. FL 08-467 resulted from direct hybridization between tetraploid southern highbush blueberry and colchicine-treated sparkleberry presumed to be tetraploid. Values above one indicate plants that are taller than wider.

Table 1. Mean, range, and coefficient of variation (Cv) for peduncle and pedicel length of 'Abundance' [ southern highbush blueberry (SHB)], FL 08-467 (SHB X sparkleberry), and a population resulting from the cross between the two parents (Progeny).

\begin{tabular}{lccccccc}
\hline & \multicolumn{3}{c}{ Peduncle } & & \multicolumn{3}{c}{ Pedicel } \\
\cline { 2 - 3 } Selection & $\begin{array}{c}\text { Mean } \\
\text { length }(\mathbf{m m})^{\mathbf{z}}\end{array}$ & $\begin{array}{c}\text { Range of } \\
\text { length }(\mathbf{m m})\end{array}$ & & $\begin{array}{c}\text { Mean } \\
\text { length }(\mathbf{m m})\end{array}$ & $\begin{array}{c}\text { Range of } \\
\text { length }(\mathbf{m m})\end{array}$ & CV \\
\hline 'Abundance' & 10 & $8-11$ & 19 & 6 & $5-6$ & 10 \\
FL 08-467 & 29 & $20-39$ & 34 & & 7 & $6-8$ & 11 \\
Progeny & 9 & $5-20$ & 39 & 5 & $3-7$ & 28 \\
\hline
\end{tabular}

${ }^{2} 1 \mathrm{~mm}=0.0394$ inch.

a population of 72 individuals resulting from the cross between 'Abundance' (tetraploid SHB) and FL 08-467 (tetraploid $\mathrm{SHB} \times$ tetraploid sparkleberry) were analyzed for plant architecture, peduncle, and pedicel length. This population represents many of the backcross populations (with respect to the recurrent genome, not an individual SHB parent) developed using the direct crossing strategy. To quantify plant architecture, the length:width ratio of the whole plant was calculated, where values above one would indicate a plant that is taller than it is wide. A histogram of the whole population showed that many individuals had a higher length:width ratio than either parent (Fig. 5). However, peduncle and pedicel lengths appeared to be more similar to the SHB parent (Table 1).

\section{Conclusions}

Sparkleberry may be useful in developing SHB cultivars adapted to MFF marketing. Similarly, efforts to use sparkleberry as a rootstock for highbush and SHB blueberry production are also underway but are outside the scope of this report. Preliminary observations suggest that 'FL 01-173' may be well suited to machine harvest for fresh fruit marketing because of its atypical upright architecture and loose fruit clusters. The breeding strategy used to develop 'FL 01-173' was arduous, but resulted in the first commercial SHB blueberry cultivar with sparkleberry in its pedigree. Currently, a direct hybridization strategy is being used to introgress sparkleberry into adapted SHB cultivars and the long-term effectiveness and importance of this effort remains to be seen.

\section{Literature cited}

Ballinger, W.E., L.J. Kushman, and D.D. Hamann. 1973. Factors affecting the firmness of highbush blueberries. J. Amer. Soc. Hort. Sci. 98:583-587.

Boches, P.S., N.V. Bassil, and L.J. Rowland. 2005. Microsatellite markers for Vaccinium from EST and genomic libraries. Mol. Ecol. Notes 5:657-660.

Brevis, P.A., N.V. Bassil, J.R. Ballington, and J.F. Hancock. 2008. Impact of wide hybridization on highbush blueberry breeding. J. Amer. Soc. Hort. Sci. 133: $427-437$.

Brooks, S.J. and P.M. Lyrene. 1998a. Derivatives of Vaccinium arboreum $\times$ Vaccinium section Cyanococcus: I. Morphological characteristics. J. Amer. Soc. Hort. Sci. 123:273-277.

Brooks, S.J. and P.M. Lyrene. 1998b. Derivatives of Vaccinium arboreum $\times$ Vaccinium section Cyanococcus: II. Fertility and fertility parameters. J. Amer. Soc. Hort. Sci. 123:997-1003.

Brown, G.K., N.L. Schulte, E.J. Timm, R.M. Beaudry, D.L. Peterson, J.F. Hancock, and F. Takeda. 1996. Estimates of mechanization effects on fresh blueberry quality. Appl. Eng. Agr. 12:21-26.

Camp, W.H. 1945. The North American blueberries with notes on other groups of Vacciniaceae. Brittonia 5:203-275.

Chavez, D.J. and P.M. Lyrene. 2010. Hybridization of two diploid Vaccinium section Cyanococcus species with diploid Vaccinium arboreum in section Batodendron. Euphytica 171:263-272.

Dale, A., E.J. Hanson, D.E. Yarborough, R.J. McNicol, E.J. Stang, R. Brennan, J.R. Morris, and G.B. Hergert. 1994. Mechanical harvesting of berry crops. Hort. Rev. 16:255-382

Ehlenfeldt, M.K. 2005. Fruit firmness and holding ability in highbush blueberry Implications for mechanical harvesting. Intl. J. Fruit Sci. 5:83-91.

Ehlenfeldt, M.K. and R.B. Martin, Jr. 2002. A survey of fruit firmness in highbush blueberry and species-introgressed blueberry cultivars. HortScience 37:386389 .

Finn, C.E., J.W. Olmstead, J.F. Hancock, and D.M. Brazelton. 2013. Welcome to the party! Blueberry breeding mixes private and public with traditional and molecular to create a vibrant new cocktail. Acta Hort. (In press).

Galletta, G.J. 1975. Blueberries and cranberries, p. 154-195. In: J. Janick and J.N. Moore (eds.). Advances in fruit breeding. Purdue Univ. Press, West Lafayette, IN.

Galletta, G.J. and C.M. Mainland. 1971. Comparative effects of mechanical harvesting on highbush blueberry varieties, p. 80-85. In: C.M. Mainland and R.P. Rohrbach (eds.). Proc. Highbush Blueberry Mech. Symp. 1-2 Nov. 1971, North Carolina State Univ., Raleigh.

Lyrene, P.M. 1991. Fertile derivatives from sparkleberry $\times$ blueberry crosses. J. Amer. Soc. Hort. Sci. 116:899-902. 
Lyrene, P.M. 1997. Value of various taxa in breeding tetraploid blueberries in Florida. Euphytica 94:15-22.

Lyrene, P. 2008. Breeding southern highbush blueberries. Plant Breeding Rev. 30:353-414.

Lyrene, P.M. 2011. First report of Vaccinium arboreum hybrids with cultivated highbush blueberry. HortScience 46: 563-566.

Lyrene, P.M. and J.W. Olmstead. 2012. The use of inter-sectional hybrids in blueberry breeding. Intl. J. Fruit Sci. 12:269275 .

Lyrene, P.M. and S.J. Brooks. 1995. Use of sparkleberry in breeding highbush blueberry cultivars. J. Small Fruit Viticult. 3:29-38.

Lyrene, P.M., N. Vorsa, and J.R. Ballington. 2003. Polyploidy and sexual polyploidization in the genus Vaccinium. Euphytica 133:27-36.
Mainland, C.M., L.J. Kushman, and W.E. Ballinger. 1975. The effect of mechanical harvesting on yield, quality of fruit and bush damage of highbush blueberry. J. Amer. Soc. Hort. Sci. 100:129-134.

Malladi, A., T. Vashisth, and L.K. Johnson. 2012. Ethephon and methyl jasmonate affect fruit detachment in rabbiteye and southern highbush blueberry. HortScience 47:1745-1749.

Moore, J.N. 1994. The blueberry industry of North America. HortTechnology 4:96-102.

Peterson, D.L., S.D. Wolford, E.J. Timm, and F. Takeda. 1997. Fresh market quality blueberry harvester. Trans. Amer. Soc. Agr. Eng. 40:535-540.

Rohrbach, R.P. and C.M. Mainland. 1989. Crown restriction in blueberries reduce harvesting ground losses. Acta Hort. 241:366-372.

Sargent, S.A., A.D. Berry, J.G. Williamson, and J. Olmstead. 2010. Fruit detachment force of southern highbush blueberry: An aid to selection of cultivars suitable for mechanical harvest. HortScience 45: S306. (abstr.).

Strik, B.C. and D. Yarborough. 2005. Blueberry production trends in North America, 1992 to 2003, and predictions for growth. HortTechnology 15:391398.

Takeda, F., G. Krewer, E.L. Andrews, B. Mullinix, Jr., and D.L. Peterson. 2008. Assessment of the V45 blueberry harvester on rabbiteye blueberry and southern highbush blueberry pruned to $\mathrm{V}$-shaped canopy. HortTechnology 18:130-138.

van Dalfsen, K.B. and M.M. Gaye. 1999. Yield from hand and mechanical harvesting of highbush blueberries in British Columbia. Appl. Eng. Agr. 15:393-398.

Vander Kloet, S.P. 1988. The genus Vaccinium in North America. Agr. Canada Publ. 1828. 